\title{
Self-Rated Anxiety and Attitude Responses of Pediatric Nurses Surveyed about Providing End of Life Care
}

\author{
Maha Mahmoud Saadoon, ${ }^{1, *}$, Mona Ibrahim Abouzeid ${ }^{1}$, \\ Ebtsam Salah Shalaby Salama ${ }^{2}$, Nadia Mohamed Wahba ${ }^{3}$ \\ ${ }^{1}$ Department of Pediatric Nursing, Nursing College, University of Port-Said, Egypt \\ ${ }^{2}$ Psychiatric and Mental Health Nursing, Elmansoura University, Egypt \\ ${ }^{3}$ Psychiatric and Mental Health Nursing, Port-Said University, Egypt \\ *Corresponding author: d.maha2010@yahoo.com
}

Received December 11, 2018; Revised February 13, 2019; Accepted March 27, 2019

\begin{abstract}
Background: End of Life care is a critical topic for pediatric patients with terminal conditions, aiming at improving their life in spite of prognosis. It is the most traumatic aspect of pediatric nursing due to unpleasant sensations and experiences that obstruct nurses' abilities to apply satisfactory care regarding End of Life. Aim: to identify the association between self-rated anxiety and attitude responses of pediatric nurses surveyed about providing End of Life care. Method: A descriptive correlational design was utilized. The sample composed of 48 nurses in neonatal and pediatric intensive care units in general hospitals in Port Said Governorate. Tools: The 20-item state anxiety questionnaire and the nurses' attitudes toward pediatric end of life care were used to collect data. Results: $46.8 \%$ of the studied nurses had demonstrated generally positive attitude toward End of Life care. $33.3 \%$ of them had tendered to reported sometimes to have anxiety symptoms, there is a statistical significant relation between level of anxiety and the attitude toward areas with comfort in discussing the pediatric End of Life care, and physician involvement. Conclusion \& Recommendation: positive attitude of pediatric nurses concerning End of Life care. Moreover, negative nurses' attitude toward the benefits of pediatric nursing care relating End of Life, and there was a statistical significant relation between level of anxiety and the attitude toward comfort in discussing the pediatric nursing care regarding End of Life, and physician involvement. Therefore, The study findings emphasize the need for acquainting pediatric nurses with effective coping strategies to overcome anxiety to improve their attitude toward End of Life care.
\end{abstract}

Keywords: attitude, end of life care, pediatric nurse, self-rated anxiety

Cite This Article: Maha Mahmoud Saadoon, Mona Ibrahim Abouzeid, Ebtsam Salah Shalaby Salama, and Nadia Mohamed Wahba, "Self-Rated Anxiety and Attitude Responses of Pediatric Nurses Surveyed about Providing End of Life Care.” American Journal of Nursing Research, vol. 7, no. 3 (2019): 316-321. doi: 10.12691/ajnr-7-3-12.

\section{Introduction}

Terminal condition in children is a life changing event for both the child, and his parents [1]. It affects children and their families physically, emotionally, and spiritually, requiring nurses to provide holistic End of Life (EOL) care that includes over than knowledge of facts and physical tasks [2]. End of Life care which is a crucial stage for both children and their family, refers to the concept of providing health care to children during the last year of their life [3].

Pediatric End of Life care is an important care in pediatric units due to a significant risk of children dying during ICUs admission. Moreover, children care before death includes very invasive and painful techniques. Additionally, children's care regarding End of Life and their parents confront crisis situations to a greater degree in ICUs than other pediatric care units. Many children with significant morbidity are returned to ICUs and die later. As a result of these situations pediatric health professionals should provide quality End of Life care that meet physical, psychological, and spiritual needs of pediatric patients and their families [4].

When the child enters the terminal phase, pediatric nurse should start End of Life care, in spite of not all of them are comfortable when caring for dying patients. Most pediatric nurses avoid the assignment if there's an actively dying patient, due to they do not have the requiring experience or comfort level to care for these patients [5,6,7].

For a pediatric nurse, the care of a child can be overwhelming, and therefore the care of a child who is dying requires even more expertise and fortitude. Nurses operating in the pediatric intensive care units experience many work stresses. In addition, provide effective care regarding End of Life for dying children patients and their families. Unfortunately, such responses have extended into professional practice [8] with nurses admitting their 
lack of EOL knowledge and skills, particularly of emotional care $[9,10]$.

Nurses who provide End of Life care for child experience anxiety and negative attitudes that in turn affect the quality of care providing for patient's. Additionally, nurses who have high levels of anxiety relating child death, are also feeling less comfortable when providing nursing care for pediatric patients at the end of their life, which conversely influence the quality of care they provide throughout the terminal stages of a child's life. Faced with emotional issues such as the reality of deaths, nurses need skills and experience to manage such fears [10].

\section{The Study's Significance}

Increasing stress on examining the experiences and wellbeing of healthcare staff providing key services so, as improve patient/career experience. Nursing staff who give End of Life care are more likely to experience high levels of emotional exhaustion and as such need special attention [11] .Although the impact of providing End of Life care to children is well documented [12], there is a lack of literature in respect to staff who work within the end of life care ([13]. So this study aims to address that gap by identifying the relationship between self-rated anxiety and attitude responses of pediatric nurses providing care regarding End of Life phase.

\section{Aim}

The research aimed to identify the association between self-rated anxiety and attitude responses of pediatric nurses surveyed about providing End of Life care.

\section{Research Question}

Are there associations between attitude responses of pediatric nurses regarding End of Life care and self-rated anxiety?

\section{Subjects and Method}

\subsection{Research Design}

A Descriptive analytical design was conducted in the present research.

\subsection{Subjects}

Participants in the current study included 48 pediatric nurses working in neonatal and pediatric intensive care units in general hospitals. They were selected on the basis of a convenient sampling technique.

\subsection{The Settings}

The present study was undertaken at neonatal and pediatric intensive care units in general hospitals in Port
Said Governorate namely, El-Nasr, Port-Said, and Port-Foaud hospitals.

\subsection{Measures of the Study}

\section{Tool I: State Trait Anxiety Inventory}

\section{Part I}

-It includes socio-demographic data such as age, sex, marital status, level of education, and experiences years.

Part II

A state anxiety portion of the state-Trait Anxiety Inventory (STAI) was used to measure self-rated anxiety of pediatric nurses [14,15] and translated by the researchers. The scale items were scored using a rating scale, with four choices ranging from "not at all" to "very much". The scale consists of 20 items with a potential range from 20 to 80 . The reliability of the scale was reported as 0.89-0.94.

\section{Tool II: Attitudes regarding End of Life Care}

Hoover [16], was modified the instrument of Bradley et al. [17] to assess attitudes regarding pediatric patients. It was translated by the researchers. The scale was 12-items survey to assess three attitudinal domains: The level of comfort, views regarding roles and responsibilities of pediatric nurses in caring for terminally ill children, and the degree of pediatric nurses' believe the beneficial care of End life. The scale items were scored using a rating scale, with five choices ranging from "strongly agree" to "strongly disagree". The scale consists of 20 items with a potential range from 20 to 80 . The reliability of the scale was reported as 0.70 .

\section{Data Collection Procedure}

\section{Interventions}

An official consent was acquired by accommodation of an official letter to the hospital director to carry out their search after clarifying the aim of the research. Pediatric nurses were requested to participate and fill the scale. The study scales were distributed, completed individually, and collected immediately after completion. Data collection took two months from January 2018 to March 2018.

\section{Statistical Analysis}

The raw data of the present study were coded. Data analysis and interpretation were carried out using SPSS version 20. Statistical measures as frequency, distribution, mean, standard deviation and Pearson correlation coefficient were used.

\section{Ethical Considerations}

- $\quad$ The study purpose was explained to all staff nurses working in a previously mentioned setting.

- Data confidentiality was assured for each participant. 


\section{Results}

Table 1 demonstrates the personal characteristics of pediatric nurses. Approximately, seventy five percent of the pediatric nurses are being in the age group less than 30 years. The mean score was $27.4 \pm 4.9$.

Table 1. Personal characteristics of the studied nurses

\begin{tabular}{|c|c|c|}
\hline \multirow{2}{*}{$\begin{array}{l}\text { Personal } \\
\text { characteristics }\end{array}$} & \multicolumn{2}{|c|}{$\begin{array}{c}\text { Studied nurses } \\
(n=48)\end{array}$} \\
\hline & No & $\%$ \\
\hline \multicolumn{3}{|l|}{ Age (years) } \\
\hline Less than 30 & 35 & 73 \\
\hline $30-<40$ & 10 & 20.8 \\
\hline $40-<50$ & 3 & 6.2 \\
\hline Mean \pm SD & \multicolumn{2}{|c|}{$27.4 \pm 4.9$} \\
\hline \multicolumn{3}{|l|}{ Marital status } \\
\hline Single & 17 & 35.4 \\
\hline Married & 30 & 62.5 \\
\hline Divorced & 1 & 2.1 \\
\hline \multicolumn{3}{|l|}{ Educational level } \\
\hline Nursing diploma & 9 & 18.7 \\
\hline Nursing institute & 25 & 52.1 \\
\hline Faculty of nursing & 12 & 25 \\
\hline Master degree & 2 & 4.2 \\
\hline \multicolumn{3}{|c|}{ Nursing experience (years) } \\
\hline$<1$ & 8 & 16.7 \\
\hline $1-<5$ & 27 & 56.2 \\
\hline 5or more & 13 & 27.1 \\
\hline
\end{tabular}

One fifth of the sample (25\%) had baccalaureate in nursing, also more than half of the sample (52.1\%) had technical certificate in Nursing. In addition, nearly two third of pediatric nurses (62.5\%) was married, compared to the reminder of the sample, $35.4 \%$ of them were still single. On the other hand, regarding nursing experience, $56.2 \%$ of the nurses have experienced less than five years. Moreover, $16.7 \%$ of the subjects have experienced less than one year in the NICU.

Attitude responses of nurses surveyed about caring for terminally ill children are shown in Table 2. The table reveals that, $46.8 \%$ of the studied nurses have demonstrated generally positive attitude toward end of life care. As for specific areas, around half of the studied nurses (55.4\%) have a positive attitude in comfort level in discussing pediatric end of life care, also $50.7 \%$ of studied nurses reported positive attitude toward physician involvement in pediatric. On the other hand, $38.5 \%$ of studied nurses have a negative attitude toward the benefits of pediatric end of life care.

Table 2. Attitudinal Responses of Nurses Surveyed about Providing End of Life Care

\begin{tabular}{|l|c|c|c|c|c|c|}
\hline \multirow{2}{*}{ Areas } & \multicolumn{2}{|c|}{ Agree } & \multicolumn{2}{c|}{ Disagree } & \multicolumn{2}{c|}{ Other } \\
\cline { 2 - 7 } & No & $\mathbf{\%}$ & No & \% & No & \% \\
\hline $\begin{array}{l}\text { Comfort with initiating end of } \\
\text { life care discussion }\end{array}$ & 133 & 55.4 & 45 & 18.8 & 62 & 25.8 \\
\hline $\begin{array}{l}\text { Perceived physician } \\
\text { responsibility }\end{array}$ & 73 & 50.7 & 47 & 32.6 & 24 & 16.7 \\
\hline $\begin{array}{l}\text { Added benefit of end of life } \\
\text { care }\end{array}$ & 64 & 33.3 & 74 & 38.5 & 54 & 28.2 \\
\hline Total & 90 & 46.8 & 55 & 28.6 & 47 & 24.6 \\
\hline
\end{tabular}

Level of anxiety of nurses surveyed about caring for terminally ill children is shown in Figure 1. The figure reveals that, $33.3 \%$ of the studied nurses have tendered to reported sometimes to have anxiety symptoms.

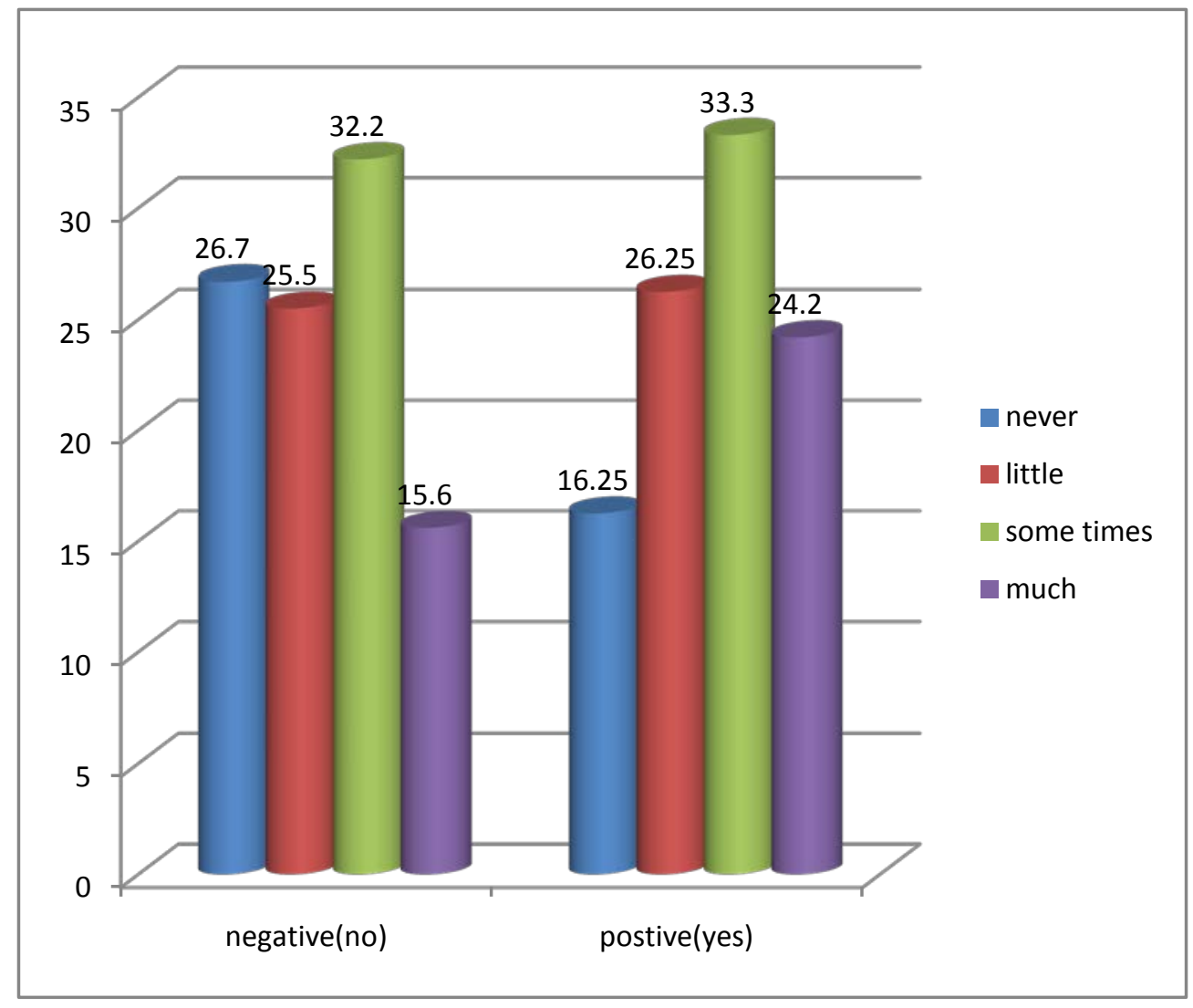

Figure 1. Level of anxiety of Nurses Surveyed about Providing End of Life Care 
Table 3: Shows the relation between the attitude and anxiety of nurses surveyed about caring for terminally ill children. It reveals that, there is a statistical significant relation between level of anxiety and the attitude toward comfort domains in discussing pediatric end of life care, and physician involvement in pediatric. Conversely, there is no statistical significant relation between level of anxiety and attitude toward the benefits of pediatric care regarding end of life.

The relation between levels of total attitude and personal characteristics of the participants is shown in Table 4. It reveals that, there is no statistical significant relation between attitude of pediatric nurses regarding End of Life care and their personal characteristics.

Table 3. Relation between the attitude and anxiety characteristics of the studied nurses toward end of life care

\begin{tabular}{|l|c|c|}
\hline \multirow{2}{*}{ Areas } & \multicolumn{2}{|c|}{ Anxiety } \\
\cline { 2 - 3 } & $\mathrm{r}$ & P-value \\
\hline Responsibility & -0.32 & $0.022^{*}$ \\
\hline Comfort & -0.45 & $0.001^{*}$ \\
\hline Benefits & -0.26 & 0.072 \\
\hline
\end{tabular}

*significance at $\mathrm{P} \leq 0.05$.

Table 4. Relation between total attitude score and socio-demographic characteristics of the studied nurses

\begin{tabular}{|c|c|c|c|}
\hline \multirow{2}{*}{$\begin{array}{l}\text { Socio-demographic } \\
\text { characteristics }\end{array}$} & \multicolumn{2}{|c|}{ Attitude } & \multirow{2}{*}{ Significance } \\
\hline & $n=48$ & Mean \pm SD & \\
\hline \multicolumn{4}{|l|}{ Age (years) } \\
\hline$<30$ & 35 & $22.7 \pm 7.8$ & \multirow{2}{*}{$\begin{array}{l}\mathrm{t}=-.847 \\
\mathrm{P}=0.401\end{array}$} \\
\hline$\geq 30$ & 13 & $29.1 \pm 3.7$ & \\
\hline \multicolumn{4}{|l|}{ Educational level } \\
\hline Nursing diploma & 9 & $28.3 \pm 2.7$ & \multirow{3}{*}{$\begin{array}{c}F=.069 \\
P=0.933\end{array}$} \\
\hline Nursing institute & 25 & $27.4 \pm 9.6$ & \\
\hline Faculty of nursing or higher & 14 & $28.0 \pm 3.5$ & \\
\hline \multicolumn{4}{|l|}{ Marital status } \\
\hline Single/divorced & 18 & $29.0 \pm 3.1$ & \multirow{2}{*}{$\begin{array}{c}\mathrm{t}=.961 \\
\mathrm{P}=0.342\end{array}$} \\
\hline Married & 30 & $27.0 \pm 8.4$ & \\
\hline \multicolumn{4}{|c|}{ Duration of experience (years) } \\
\hline Less than 1 & 8 & $27.2 \pm 13.4$ & \multirow{3}{*}{$\begin{array}{l}F=0.024 \\
P=0.977\end{array}$} \\
\hline $1-<5$ & 27 & $27.8 \pm 6.0$ & \\
\hline$\geq 5$ & 13 & $27.8 \pm 2.4$ & \\
\hline
\end{tabular}

*Significance at $\mathrm{P} \leq 0.05$.

\section{Discussion}

Pediatric nurses who working in children's hospitals often provide care for terminally ill children. Little is known regarding their beliefs and experiences as hospital staff concerning providing care for those patients [18]. So, this study was undertaken to identify the association between self-rated anxiety and attitudinal responses of pediatric nurses providing care regarding end of life.

Using survey data from pediatric nurses in port-said hospitals, the findings of the present study shown that, $46.8 \%$ of the studied pediatric nurses had demonstrated generally positive attitude toward End of Life care. On the opposite view, this point of the study results is disagreement with other research findings, which indicated that a majority of pediatric nurses have a negative attitude regarding End of Life care [19,20]. This may be due to that one fifth of the sample in the current study had baccalaureate in Nursing, and more than half of them had technical certificate in Nursing, this increase chance for educational training concerning the care of End Life. Furthermore, a previous study has found a positive relationship between nurses' attitude and their awareness regarding EOLC [21].

Concerning specific area of attitude response, more than half of the studied nurses have a positive attitude of comfort in discussing the pediatric End of Life care. This research finding is corresponding to the study findings of Tripathy et al. [22] who found that the majority of pediatric nurses (81.9\%) agreed that they should be involved in EOL discussions with the child and his family, nearly $62.3 \%$ felt that they should be among the first to initiate these discussions. On the opposite side, the family wants to discuss related issues, as well, but pediatric nurses feel more comfortable leaving such discussions with someone else [23].

Possible explanation may regard to that the experience in nursing in the current study as the result shows that more than half of the nurses had experienced one year to less than five years. This explanation supported by a study conducted by Feudnter et al. [24] who reported that nurses with more years of nursing practice and higher levels of hope were more comfortable in providing care to dying children and their families, had less difficulty talking about death and dying, and showed high levels of End of Life care competency. This finding was in the same line with the study, which concluded that working experience has more effect on pediatric nurses' attitude regarding discussing pediatric EOLC [20].

It was noticed that about half of the studied nurses reported positive attitude toward physician involvement in pediatric care relating End of Life. It is appointed out that interdisciplinary teamwork improves clinical outcomes as well as child's satisfaction and decreases hospital costs [25]. Correspondingly, collaborative relations between medical staff and pediatric nurses can positively affect the outcomes of patient care and patient death rates [26]. Medical staff has rated collaboration levels higher than their nursing counterparts, while pediatric nurses have valued collaboration more significantly positive than medical staff [27]. Possible explanation may regard to that pediatric nurses in the present research perceived the above behaviors showed by physicians as very helpful behaviors that occur frequently in the provision of End of Life care.

On the other hand, $38.5 \%$ of the studied nurses have a negative attitude toward the benefits of pediatric End of Life care. This may regard to that despite the fact that the critical units as ICUs is viewed as a serious life-saving area, various children die in the unit, and the urgency associated with the End of Life decisions for these pediatric patients creates challenges for the nurses providing this type of care. So, pediatric nurses whose daily practice based on saving children's lives, a sudden change in their condition which requiring the End of Life care can cause a disconnect between what pediatric nurses routinely do in the and what they are now expected to do.

Critical settings of pediatric patients emphasize curative and aggressive lifesaving treatment [28]. Inversely, when the condition of a terminally ill child does not respond to 
aggressive treatment, the transition to End of Life care is essential. However, a pediatric nurses who are being faced with a pediatric patient who is in the dying phase, or has died, can be distressed [29].

Based on this, there is no statistical significant relation between level of self rated anxiety and attitude toward the benefits of the pediatric care regarding End of Life in the present study. Although the researchers, namely Ek et al., [30] and King-Okoye and Arber [31] states that Emotions about death and the care of the dying are reflected in attitudes, which encompass feelings, values, and beliefs. Negative emotions have clearly demonstrated an effect on EOL care.

Finally, there is a statistical significant relation between level of anxiety and the attitudinal responses of comfort in discussing the pediatric End of Life care and physician involvement. This may be due to the present research results which concluded that about one third of the pediatric nurses sometimes had anxiety symptoms, and these attitude responses need more expertise and stable character to discuss such matters which increase a sense of reasonability and anxiety level, as based upon how End of Life care is acquainted with a family, the demonstration of discussion might be mixed up as synonymous with "surrendering" or "setting up" care which can prompt to a refusal of care.

\section{Conclusion \& Recommendations}

The research findings showed a positive attitude regarding pediatric End of Life care, which includes comfort domains in discussing End of Life care, and the attitude toward health care professionals as doctors and pediatric nursing. On the other hand, there was negative attitude toward the benefits of pediatric end of life care. Furthermore, pediatric nurses showed some degrees of anxiety, in spite of most of pediatric nurses scored themselves on the lower end of the anxiety tool. Unfortunately, the information which gained from these results to develop a teaching tool directly was not enough. Therefore, The research results concluded the need for teaching pediatric nurses the effective coping strategies to prevent anxiety, which help them to improve their attitude regarding End of Life care.

\section{References}

[1] Warwick, B., (2012). Outcome after pediatric intensive care unit discharge. Journal of Pediatrics, 88, 1-3.

[2] Ward Betsy, N., Kennesaw. (2017). Nursing Students’ Knowledge and Attitudes Toward Care of the Dying,Doctorate of Nursing Science Dissertations, Wellstar School of Nursing Fall 12-12.

[3] Robinson, J., Gott, M. \&Ingleton, C. (2014). Patient and family experiences of palliative care in hospital: What do we know? An integrative review. Palliative Medicine, 28 (1), 18-33.

[4] Ali, W.G., \&Ayoub, N.S. (2010). Nurses' perception towards caring for end of life pediatric patient in Mansoura University Hospitals. Journal of Medical and Biomedical Science. 5, 16-23.

[5] Cevik, B., \& Kav, S. (2013). Attitudes and experiences of nurse toward deathand caring for dying patients in Turkey. Cancer Nursing, 36(6), 58-65.

[6] Raphael, D., Waterworth, S., \& Gott, M. (2014). The role of practice nurses in providing palliative and End of Life care to older patients with long-termconditions. International Journal of Palliative Nursing, 20(8), 373-9.

[7] Tan, A., \& Manca, D. (2013). Finding common ground to achieve a "gooddeath": Family physicians working with substitute decision-makers of dying patients. Aqualitative grounded theory study. BMC Family Practice, 1414.

[8] Bloomer, M. J., Endacott, R., O'Connor, M., \& Cross, W. (2013). The 'disease' of dying: Challenges in nursing care of the dying in the acute hospitalsetting. A qualitative observational study. Palliative Medicine, 27(8), 757-64.

[9] Cui, J., Shen, F., Ma, X., \& Zhao, J. (2011). What do nurses want to learn from death education? A survey of their needs. Oncology Nursing Forum, 38(6), p 402-8.

[10] Peters, L., Cant, R., Payne, S., O'Connor, M., McDermott, F., Hood, K., Shimoinaba, K. (2013). How death anxiety impacts nurses' caring for patients at the end of life: A review of literature. Open Nursing Journal, 7, 14-21.

[11] Maben, J., Peccei R., Adams, M., Robert, G., Richardson, A., Murrells, T., et al. (2012). Patients' experiences of care and the influence of staff motivation, affect and well-being. Final Report. NIHR Service Delivery and Organization Program. http:// www.nets.nihr.ac.uk/_data/assets/pdf_file/0007/85093/ES-081819-213.pdf. Accessed 10 Feb 2016.

[12] Klassen, A., Gulati, S., Dix D. (2012). Health care Providers' perspectives about working with parents of children with cancer: A qualitative study. Journal of Pediatric Oncology Nursing, 29, 92-7.

[13] McConnell, T., Scott, D., Porter S. (2016). Healthcare staff experience of providing end of life care to children: a mixed method review. Pall Med.

[14] Spielberger, C., (1983). Manual for the State-Trait Anxiety Inventory. (rev. ed.). Palo Alto, (CA): Consulting Psychologists Press.

[15] Spielberger, C. D. (1985). Assessment of state trait anxiety: conceptual and methodological issues. The Southern Psychologist, 2, 6-16.

[16] Hoover, T. L,( 2006). "The relationship between nurses' anxiety and attitude related to pediatric hospice" Graduate Theses and Dissertations. https://scholarcommons.usf.edu/etd/2563

[17] Bradley, E. H., Cicchetti, D. V., Fried, T. R., Rousseau, D. M., Johnson-Hurzeler, R., Kasl, S. V., et al. (2000). Attitudes about care at the end of life among clinicians: a quick, reliable, and valid assessment instrument. Journal of Palliative Care, 16, 6-14.

[18] Tubbs-Cooley, H L.., Santucci, G., APRN. B C, Tammy I. K., James A. F,., Kari R. H., \& Feudtner, Chris. (2011). Pediatric Nurses’ Individual and Group Assessments of Palliative, End of Life, and Bereavement Care.Journal of palliative medicine, 14(5).

[19] Razban F, Iranmanesh S, Rafiei H. Nurses' attitudes toward palliative care in southeast Iran. International Journal of Palliative Nursing. Aug; 19(8): 403-10.

[20] Hussin E. O. D. Wong L. P. Chong M. C. Subramanian P. (2018). Factors associated with nurses' perception about quality of end-of-life care. International Nursing Review, 65 (2).

[21] Beccaro, M., Caraceni, A., Costantini, M. \& ISDOC Study Group (2010): End-of-life care in Italian hospitals: quality of and satisfaction with care from the caregivers' point of view-results from the Italian Survey of the Dying of Cancer. Journal of Pain and Symptom Management, 39, 1003-15.

[22] Tripathy S, Pragyan K. Routray, and Jagdish C. Mishra. (2017). Intensive Care Nurses' Attitude on Palliative and End of Life Care. Indian J Crit Care Med. Oct, 21(10), 655-9.

[23] Jackson, J., Derderian, L., White, P., Ayotte, J., Fiorini, J., Osgood Hall, R., \& Shay, J.T. (2012, June). Family perspective on End of Life care. Journal of Hospice and Palliative Nursing, 14(4), 303311.

[24] Feudtner C, Santucci G, Feinstein JS, Snyder CR, Rourke MT, Kang TI. (2007). Hopeful thinking and level of comfort regarding providing pediatric palliative care: A survey of hospital nurses. Pediatrics, 119(1): e186-e192.

[25] Havyer R. D. A ,Wingo M. T., Comfere N. I. et al. (2014). "Teamwork assessment in internal medicine: a systematic review of validity evidence and outcomes," Journal of General Internal Medicine, 29 (6), 894-910,

[26] Boev, C and Xia, Y(2015). "Nurse-physician collaboration and hospital-acquired infections in critical care," Critical Care Nurse, 35(2), 66-72. 
[27] Wang Y., Liu Y., Li H.,\& Li T. (2015). Attitudes toward Physician-Nurse Collaboration in Pediatric Workers and Undergraduate Medical/Nursing Students Hindawi Publishing Corporation. Behavioural Neurology, 2015, Article ID 846498, 6 pages.

[28] Moawad, G.N.A. (2013). Nurses perception of obstacles and supportive behaviors in providing end of life care to critically ill pediatric patients. Journal of Biology, Agriculture and Healthcare, 3(2), 95-105.

[29] Louw, N. (2016). Pediatric nurses’ perception of obstacles and supportive behaviors in end of life care in pediatric intensive care units. Master thesis, Johannesburg

[30] Ek, K., Westin, L., Prahl, C., Österlind, J., Strang, S., Bergh, I., . . Hammarlund, K. (2014). Death and caring for dying patients: Exploring first-year nursing students' descriptive experiences. International Journal of Palliative Nursing, 20(10), 509-515.

[31] King-Okoye, M., \& Arber, A. (2014). 'It stays with me': The experiences of second- and thirdyear student nurses when caring for patients with cancer. European Journal of Cancer Care, (4), 441.

(C) The Author(s) 2019. This article is an open access article distributed under the terms and conditions of the Creative Commons Attribution (CC BY) license (http://creativecommons.org/licenses/by/4.0/). 